\title{
A parabolic trough solar collector as a solar system for heating water: a study based on numerical simulation
}

\author{
Mokhtar Ghodbane $^{1}$, Boussad Boumeddane ${ }^{1}$ \\ ${ }^{1}$ Department of Mechanical Engineering, University of Saâd DAHLAB, Blida 1, ALGERIA \\ ghodbanemokhtar39@yahoo.com
}

\begin{abstract}
This paper is an optical and thermal study of a small model of a parabolic trough solar collector (CTP), which will be used to heat tap water, in the winter, at Guemar location, (ElOued, Algeria). A mathematical model was presented based on the energy balance equation applied to the absorber tube; this model was solved by the finite difference method. A computer program based on MATLAB was developed to solve the problem. The results show that the thermal efficiency of the concentrator can attend a high value of more than $61 \%$, while the fluid outlet temperature can reach $343 \mathrm{~K}$.
\end{abstract}

Keywords: Solar thermal, parabolic trough collector, outlet temperature, Tap water, numerical analysis.

Received: 09/10/2017 - Accepted: 25/12/2017

\section{Introduction}

The oldest and the greatest source of energy in the universe is the sun, where an average of $1367\left(\mathrm{~W} / \mathrm{m}^{2}\right)$ reached the edge external of the terrestrial atmosphere according to the world radiometric center of Davos (Switzerland) [1].

The global solar radiation is the sum of both direct and diffuse components [2-16]. Algeria has one of the highest solar radiation in Africa. The sunshine duration on almost all of the national territory exceeds 2000 hours annually and can reach 3900 hours in the Highlands and Sahara [17].

Table 1. The meteorological data of the city of Guemar.

\begin{tabular}{|c|c|c|c|c|c|c|}
\hline Month & $\begin{array}{c}\text { Global } \\
\text { Radiation } \\
\left(\mathrm{kWh} / \mathrm{m}^{2}\right)\end{array}$ & $\begin{array}{c}\text { Diffuse } \\
\text { Radiation } \\
\left(\mathrm{kWh} / \mathrm{m}^{2}\right)\end{array}$ & $\begin{array}{c}\text { Beam } \\
\text { Radiation } \\
\left(\mathrm{kWh} / \mathrm{m}^{2}\right)\end{array}$ & $\begin{array}{c}\text { Monthly average } \\
\text { of ambient } \\
\text { temperature } \\
\left({ }^{\circ} \mathrm{C}\right)\end{array}$ & $\begin{array}{c}\text { Monthly average } \\
\text { of dew point } \\
\left({ }^{\circ} \mathrm{C}\right)\end{array}$ & $\begin{array}{c}\text { Monthly average } \\
\text { of wind } \\
\text { speed } \\
(\mathrm{m} / \mathrm{s})\end{array}$ \\
\hline 1 & 114 & 19 & 211 & 10,6 & 4 & 2,1 \\
\hline 2 & 125 & 28 & 184 & 12,9 & 3,1 & 2,5 \\
\hline 3 & 170 & 48 & 197 & 17,8 & 4,6 & 3,3 \\
\hline 4 & 207 & 54 & 225 & 21,6 & 7,1 & 4,1 \\
\hline 5 & 234 & 69 & 237 & 26,8 & 9,6 & 3,6 \\
\hline 6 & 236 & 70 & 228 & 31,3 & 11,4 & 3,4 \\
\hline 7 & 248 & 66 & 242 & 34,7 & 13,3 & 3 \\
\hline 8 & 219 & 67 & 217 & 33,8 & 14,6 & 2,2 \\
\hline 9 & 176 & 55 & 187 & 28,8 & 15 & 2 \\
\hline 10 & 144 & 45 & 179 & 23,8 & 12,7 & 2,3 \\
\hline 11 & 117 & 21 & 200 & 16,1 & 7,3 & \\
\hline 12 & 100 & 21 & 187 & 11,7 & 5,1 & \\
\hline
\end{tabular}

For the PTC solar concentrator, it gives us a temperature of fluid that can be used both in industrial and domestic applications, with a medium- to high range
This study deals with the exploitation of solar energy to produce hot water using parabolic trough concentrator (PTC) in Guemar region, where the table (1) shows the meteorological data of this city. In previous studies, we have studied several models of this system in different regions in Algeria, where the results were very encouraging [2-11]. of $\left[80-160^{\circ} \mathrm{C}\right][2-6,9,11]$. According to the size and position of the PTC collector, this system can obtain a steam temperature exceeding $1500{ }^{\circ} \mathrm{C}$, according to 
studies cited in the scientific literature $[3-6,9,11,18]$. So, the PTC systems are the most currently used technology by the most powerful solar power plants in the world, we quote in this context that the solar plant at Kramer Junction in California represents a total installed capacity of $354 \mathrm{MW}$ [19]. This kind of solar field is made up of parallel alignments of long half-cylindrical mirrors, oriented North-South axis that revolved around the latter to follow the path of the Sun. The Sun's rays are concentrated on a horizontal tube, where circulates a heat transfer fluid.
As we said earlier, this study focuses on the conversion of solar energy to thermal energy by using a parabolic trough solar concentrator in a troubled day of the winter (Low-temperature weather with some wind). Tap water was used as the heat transfer fluid. Our aim in this study is to characterize the optical and thermal efficiencies of our PTC model based on the geographic parameters and climatic conditions in Guemar location, (El-Oued, Algeria). Figure 1 shows the scheme of the approved water heating system using TRNSYS 16.

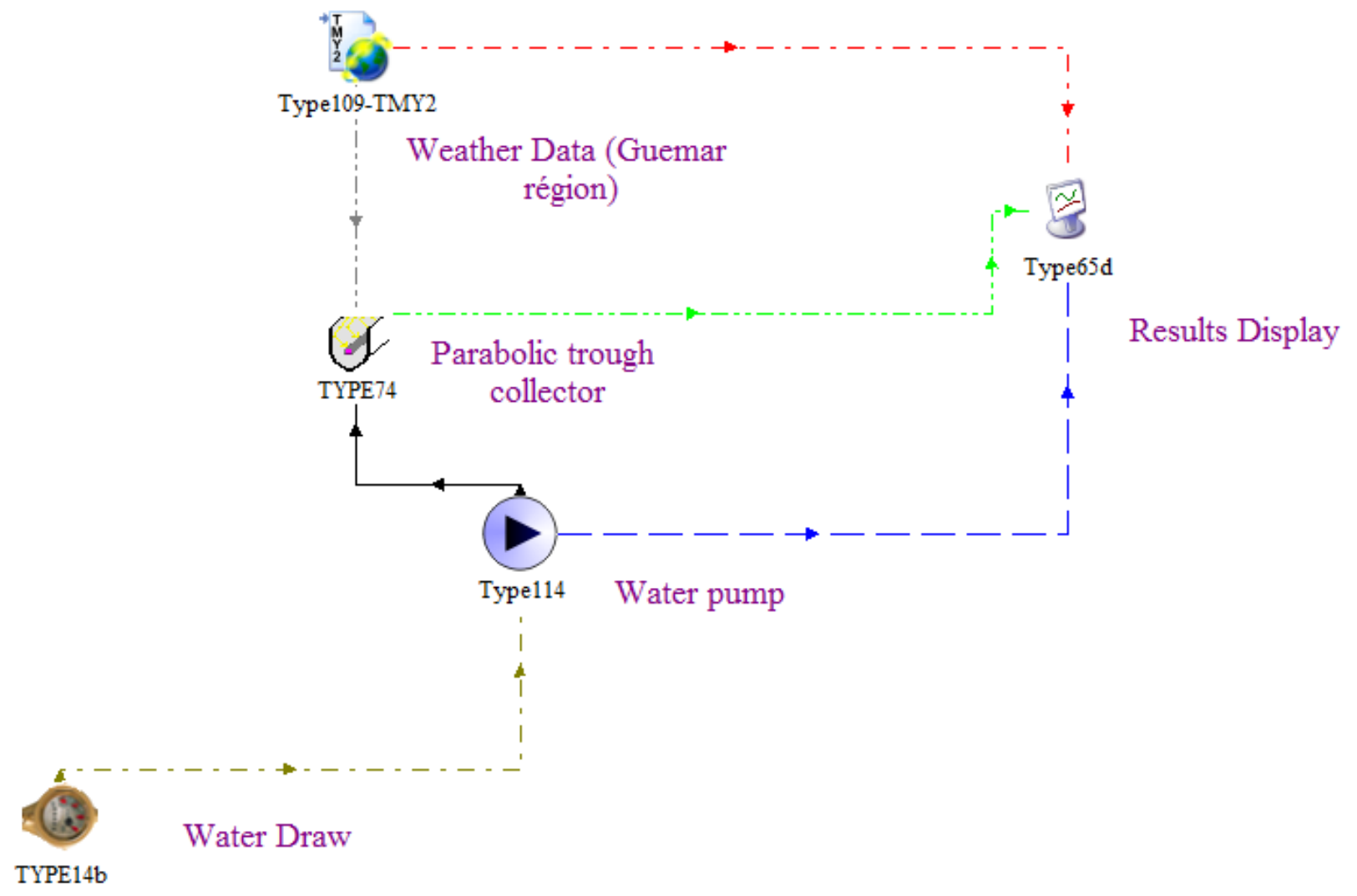

Figure 1. Illustrative diagram of the water heater system.

In order to solve to problem, this study will begin with an optical efficiency analysis using SolTrace software. In the second step, a mathematical model has been established with Matlab to calculate the thermal efficiency, the fluid outlet temperature, the receiver's surface temperature, the glass temperature and the coefficient of thermal losses.

\section{Optical simulation}

The optical modeling was performed using the SolTrace; the code is developed by the National Renewable Energy Laboratory (USA) [20]. The optical system of the concentrator is composed of the reflecting surface and absorber tube. The reflecting surface was modeled as a single mirror of parabolic section. Table (2) shows the geometric parameters of the PTC concentrator and the optical parameters are shown in Table (3).
Table 2. Geometrical parameters of the PTC collector.

\begin{tabular}{lc}
\hline geometric characteristic & Value (mm) \\
\hline Receiver tube number & 1 \\
Absorber length $\left(\mathrm{L}_{\mathrm{A}}\right)$ & 12270 \\
outer diameter of the absorber $\left(\mathrm{D}_{\mathrm{A}, \text { ext }}\right)$ & 22 \\
Inner diameter of the absorber $\left(\mathrm{D}_{\mathrm{A}, \text { int }}\right)$ & 20 \\
outer diameter of the glass $\left(\mathrm{D}_{\mathrm{V}}, \mathrm{ext}\right)$ & 26 \\
inner diameter of the glass $\left(\mathrm{D}_{\mathrm{V}, \text { int }}\right)$ & 23,5 \\
mirror length $(\mathrm{L})$ & 12270 \\
mirror width $(\mathrm{l})$ & 1100 \\
\hline
\end{tabular}

The absorbent tube dimensions mentioned in the previous table are the dimensions of a linear Fresnel receiver that was previously manufactured by $\mathrm{H}$. Chabahi et al., (2011) [21], but the length of the absorbent tube here was different. 
For the optical simulation, it was assumed that the reflection coefficient, the absorptivity, and transmissivity are uniform over the entire reflecting surface. It was considered that the solar tracking is very accurate and therefore the concentrator opening is constantly perpendicular to the rays from the solar disc.

Table 3. Optical parameters of the collector.

\begin{tabular}{lc}
\hline \multicolumn{1}{c}{ parameter } & Value \\
\hline optical overall average error $\left(\sigma_{\text {optical }}\right)$ & $03 \mathrm{mrad}$ \\
mirror reflection coefficient $\left(\rho_{\mathrm{m}}\right)$ & 0,92 \\
Transmissivity of the glass & 0,945 \\
Absorption coefficient of the absorber $(\alpha)$ & 0,94 \\
The emissivity of the absorber tube $\left(\varepsilon_{\mathrm{A}}\right)$ & 0,12 \\
\hline
\end{tabular}

There are several models for the simulation of global direct and diffuse solar irradiance, expressed by semiempirical approaches.

For the PTC concentrators, the absorbed solar energy depends on the beam radiation (DNI) $[3-6,9,11]$. Figure 2 reflects the change in the solar radiation during the day of 05 December 2016 according to the semi-empirical model of PERRIN DE BRICHAMBAUT, where M. Ghodbane et al., (2016), had created a numerical simulation based on programming using MATLAB for the calculation of solar radiation (direct, diffuse and global) [8]. For this model, the different components of the solar radiation vary according to the height of the sun, the angle of incidence, the weather condition and the state of visibility of the atmosphere.

Any application of solar energy in a given site requires a complete and detailed knowledge of the sunshine of the site. This is possible if the data are available over a sufficient period. However, in the majority of cases, there are no local measurements of solar radiation, and some approximate methods must be used to predict the characteristics of solar irradiation.

The total quantity of radiation calculated for a particular location or area was entered as global radiation. The calculation radiation (direct, diffuse and global) was repeated for each entity location or for all locations of the topographic surface and generates sunshine maps for an entire geographical area.

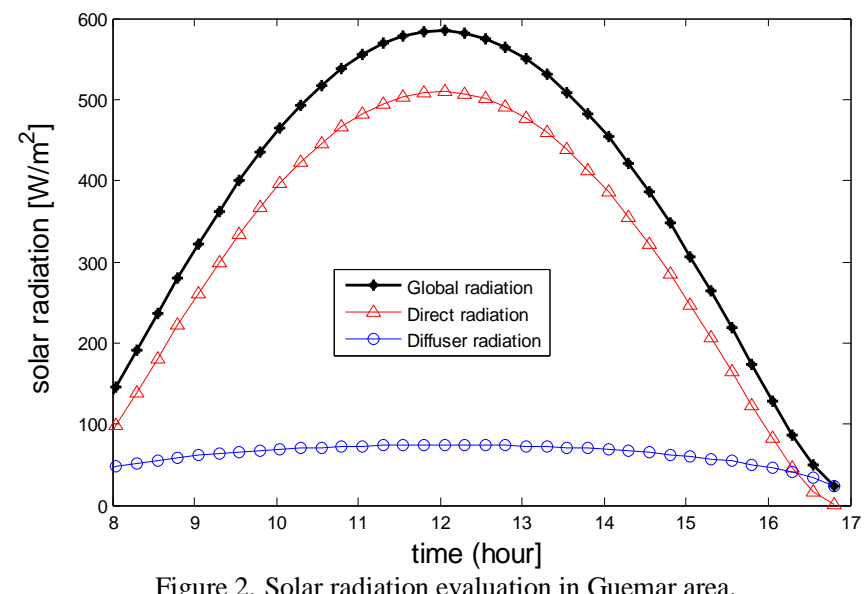

Figure 2. Solar radiation evaluation in Guemar area.
Virtually, it was in the regions for which we had the least solar radiation measurements that the projects of implantation of the solar energy systems for water pumping, desalination, or the decentralized electric power supply are the most important and the most demanding. Direct radiation (DNI) is solar radiation reaching the earth's surface directly from the sun. It depends on the thickness of the atmosphere that the solar radiation must cross, as well as the inclination of the rays relative to the ground. The PYRHELIOMETER is the instrument for measuring the intensity of direct radiation. The PYRHELIOMETER must be equipped with a device to direct it permanently towards the sun. Through Figure 2 , it was noticeable that the maximum radiation value is the true solar noon, which can reach $585\left(\mathrm{~W} / \mathrm{m}^{2}\right)$, despite the bad weather on this day, the amount of solar radiation was considered.

Figure 3 illustrates the captured solar energy by the collector, as presented in SolTrace. We tried to show the importance and effectiveness of parabolic trough collector in the field of solar concentrate.

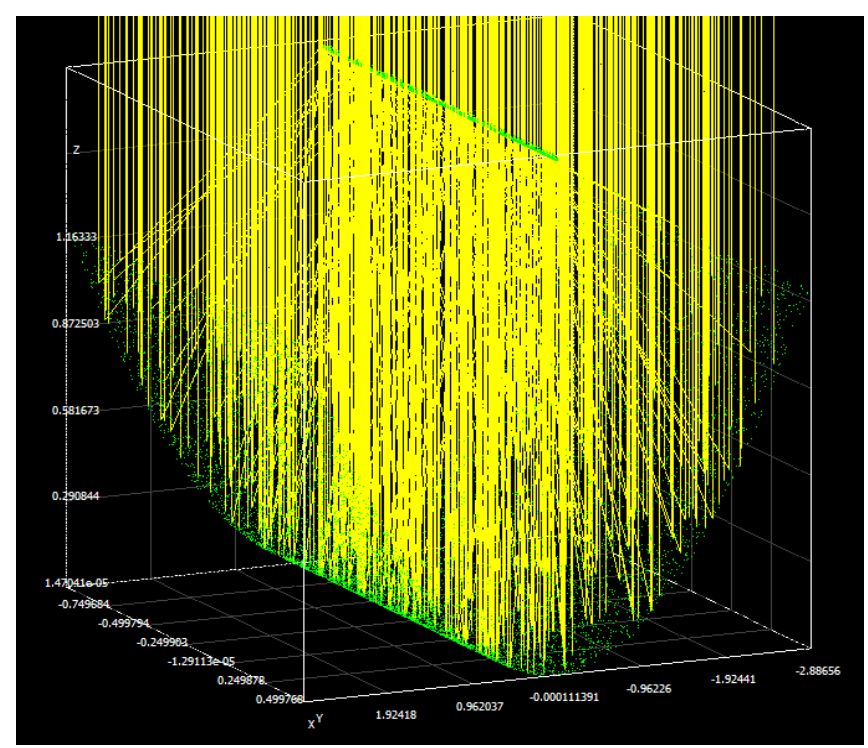

Figure 3. Schema parabolic trough concentrator as it appears in SolTrace.

\section{Thermal simulation}

This section treats the thermal analysis and numerical modeling of a PTC concentrator. This modeling was used to predict the change in the outlet temperature of the heat transfer fluid (water) versus the beam radiation. The thermal exchanges are between the heat transfer fluid, the absorber tube and the glass tube. The temperature modeling was based on the energy balances characterized by the differential equations of the three temperatures: $T_{F}$ (for the fluid), $\mathrm{T}_{\mathrm{V}}$ (for glass tube) and $\mathrm{T}_{\mathrm{A}}$ (for the absorber tube), these equations will vary depending on 
two parameters, namely the time (t) and the length (x) of the absorber tube. In calculating the energy balances, we have assume that $[9,13]$ :

- The heat transfer fluid is incompressible;

- The parabolic shape is symmetrical;

- The ambient temperature around the concentrator is uniform;

- The shadow effect of the absorber tube on the mirror is negligible;

- The solar flux at the absorber is uniformly distributed;

- The glass is considered opaque to infrared radiation;

- The exchanges by conduction in the absorber and the glass are negligible.

\section{III.1. Energy balance for the fluid}

The energy balance for the heat transfer fluid that circulates in the absorber tube was expressed by the following relationship $[2,5,7,10,11]$ :

$$
\begin{array}{r}
\rho_{F} \cdot C_{F} \cdot A_{A, \mathrm{int}} \cdot \frac{\partial T_{F}(X, t)}{\partial t}= \\
q_{u}-\rho_{F} \cdot C_{F} \cdot Q_{v} \cdot \frac{\partial T_{F}(X, t)}{\partial X}
\end{array}
$$

The initial conditions and the boundary conditions of equation (1) are $[2,5,10,11]$ :

$$
\begin{aligned}
& \mathrm{T}_{\mathrm{F}}(0, \mathrm{t})=\mathrm{T}_{\mathrm{F}, \text { entry }}(\mathrm{t})=\mathrm{T}_{\mathrm{amb}}(\mathrm{t}) \\
& \mathrm{T}_{\mathrm{F}}(\mathrm{X}, \mathrm{t})=\mathrm{T}_{\mathrm{F} \text {,initial }}(\mathrm{t})=\mathrm{T}_{\mathrm{amb}}(0)
\end{aligned}
$$

$\mathrm{q}_{\mathrm{u}}$ is the heat flow transmitted to the fluid [W]; it was given by the following relationship $[3,10,14]$ :

$$
q_{u}=h_{F} \cdot A_{A, \mathrm{int}}\left(T_{A}-T_{F}\right)
$$

\section{III.2. Energy balance for the absorber tube}

The energy balance for the absorber was given by the following equation $[2,5,7,10,11]$ :

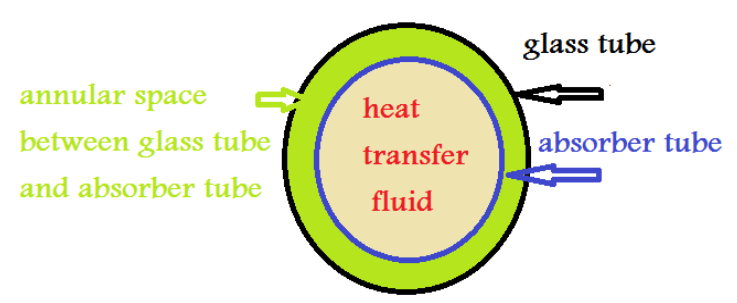

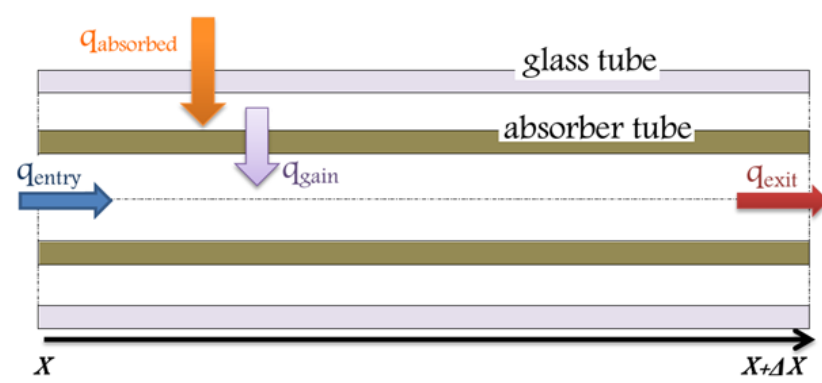

Figure 4. Thermal balance on a surface element of the parabolic cylindrical concentrator [3].

$$
\begin{aligned}
& \rho_{A} \cdot C_{A} \cdot A_{A} \cdot \frac{\partial T_{A}(X, t)}{\partial t}= \\
& q_{\text {absorbed }}(t)-q_{\text {exit }}(X, t)-q_{u}(X, t)
\end{aligned}
$$

The initial conditions for the equation (4) are [5, 10, 11]:

$$
T_{A}(X, t)=T_{A, \text { initial }}(t)=T_{\text {amb }}(0)
$$

\section{III.3. Energy balance of the glass}

Similarly, the energy balance for the glass was given by $[2,5,7,10,11]$ :

$$
\begin{aligned}
& \rho_{V} \cdot C_{V} \cdot A_{V} \cdot \frac{\partial T_{V}(X, t)}{\partial t}= \\
& q_{\text {int }}(X, t)-q_{\text {ext }}(X, t)
\end{aligned}
$$

The initial condition of equation (6) is $[5,10,11]$ :

$$
T_{V}(X, t)=T_{V, \text { initial }}(t)=T_{a m b}(\mathrm{O})
$$

To solve this problem, we chose the finite difference method. A calculation program Matlab was established, after the discretization of non-linear equations that allowed us to obtain a set of numerical results.

The thermal power emitted by the sun and received by the concentrator is therefore $[5,10,11,22]$ :

$$
q_{\text {absorbed }}=\rho_{m} \cdot \gamma \cdot A_{c} \cdot K_{\text {cam }} \cdot D N I
$$

Where $\mathrm{K}_{\mathrm{cam}}$ is Angle of incidence correction factor modified, $\gamma$ is the intercept factor.

We can express the optical efficiency $\left(\eta_{\text {opt }}\right)$ of the concentrator $[5,10,11,15]$ :

$$
\eta_{o p t}=\alpha \cdot \rho_{\mathrm{m}} \cdot \gamma \cdot K_{c a m}
$$

The thermal efficiency $(\eta)$ was calculated as follows [2, 
$5,10,11,15]:$

$$
\eta=\eta_{o p t}-\frac{U_{L} \cdot A_{A} \cdot\left(T_{A}-T_{a m b}\right)}{D N I \times A_{C}}
$$

\section{III.4. The coefficient of thermal losses}

The coefficient of thermal losses $\left(\mathrm{U}_{\mathrm{L}}\right)$ was expressed as $[2,5,7,10,11]$ :

$$
\begin{aligned}
& U_{L}=\left(\frac{1}{C_{1}\left[\frac{T_{A}-T_{a m b}}{1+f}\right]^{0.25}}+\frac{D_{A, \text { int }}}{D_{A, \text { ext }} \times h_{v}}\right)^{-1}+ \\
& \frac{\sigma\left(T_{A}^{2}+T_{a m b}^{2}\right) \cdot\left(T_{A}+T_{a m b}\right)}{\left[\varepsilon_{A}-0.04\left(1-\varepsilon_{A}\right)\left(\frac{T_{A}}{450}\right)\right]^{-1}-\left[\left(\frac{D_{A, \text { int }}}{D_{A, \text { ext }}}\right)\left(\frac{1}{\varepsilon_{V}}\right)\left(\frac{f}{\varepsilon_{V}}\right)\right]}
\end{aligned}
$$

Where the factor $(f)$ takes into account the loss ratio resulting from the wind, it can be obtained by the following equation $[5,10,11]$ :

$$
\begin{array}{r}
f=D_{A, \text { int }}^{-0.4}\left(1.61+1.3 \varepsilon_{A}\right) h_{v}^{-0.9} \times \\
\exp \left[0.00325\left(T_{A}-273\right)\right]
\end{array}
$$

C1 was given by the following empirical expression $[5,10,11]$ :

$$
C_{1}=\frac{1.45+0.96\left(\varepsilon_{A}-0.5\right)^{2}}{D_{A, \text { int }}\left(\frac{1}{D_{A, \text { int }}^{0.6}-D_{A, \text { ext }}^{0.6}}\right)^{1,25}}
$$

The term (hv) is the wind convection coefficient, it can be obtained by the following equation (according McAdams (1954)) [5, 10, 11, 15, 23]:

$$
h_{v}=5.7+3.8 W_{W}
$$

\section{Results and discussion}

The PTC concentrators can offer an opportunity to sunny countries such as Algeria for investment and construction of solar central.

The right choice of the studied site is very important because each site is characterized by its direct illumination, the ambient temperature, the speed of the wind, the latitude, and the elevation compared to the level of the sea, which play a significant role on the profitability of the solar concentrator. These factors were quite apparent in the results obtained where the energy production vary when moving the solar collector in different sites. We selected Guemar city to conduct this study, it is located at an altitude of 62 meters with a latitude and longitude of $33^{\circ} 29^{\prime} 24^{\prime \prime} \mathrm{N}$ north and 06 47'50" East respectively. PTC concentrator had headed south. We chose tap water as the working fluid with a flow rate of $0.015[\mathrm{~kg} / \mathrm{s}]$.

The absorber was the seat of the thermal conversion (from concentrated solar radiation into high temperature heat sensitive). On wall of the absorber tube, the thermal energy acquired from the sun has propagated by direct contact of the particles without appreciable displacement of the latter. Figures $5 \mathrm{a}$ and $5 \mathrm{~b}$ reflect the average intensities contours of heat flux on the absorber surface based on the direct solar radiation (DNI).

\section{a) $\mathrm{DNI}=1000\left[\mathrm{~W} / \mathrm{m}^{2}\right]$}

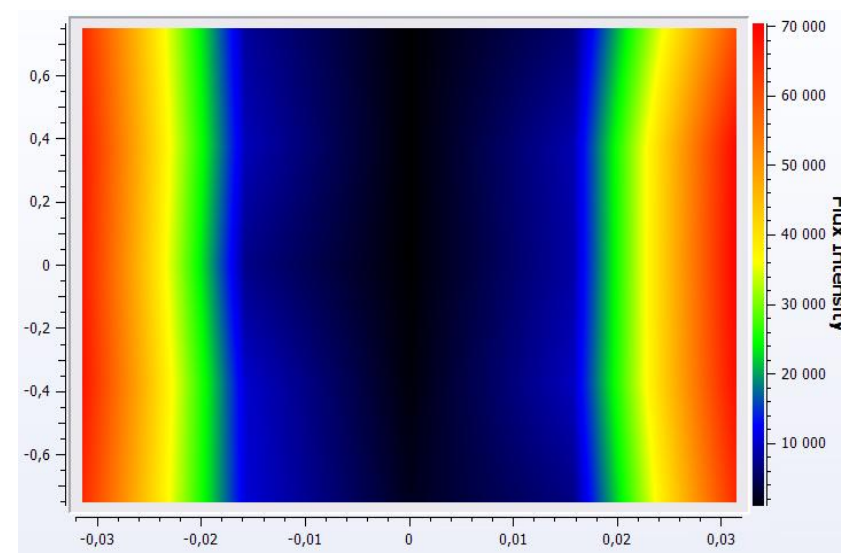

b) $\mathrm{DNI}=500\left[\mathrm{~W} / \mathrm{m}^{2}\right]$

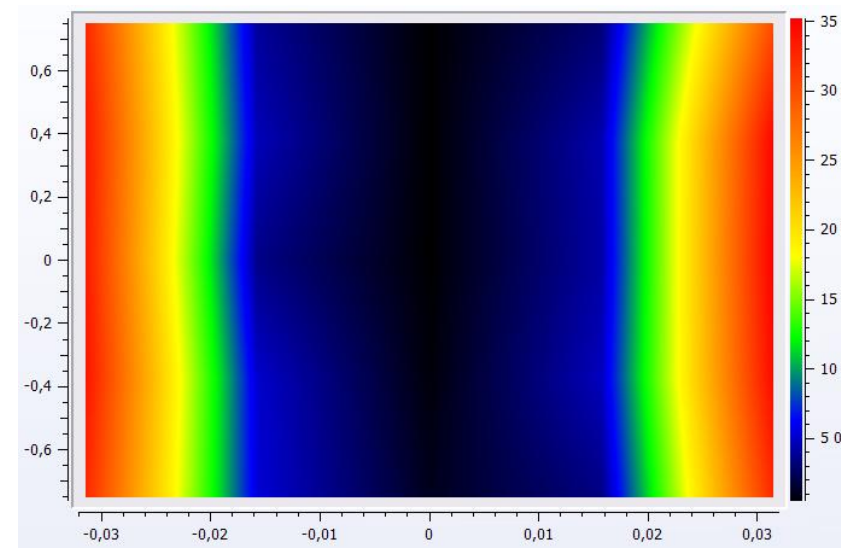

Figure 5. Flux intensity contour at the absorber tube $\left[\mathrm{W} / \mathrm{m}^{2}\right]$.

This assessment can approach the actual values of thermal flow influencing absorbers with a reflectivity of the mirrors equal to $92 \%$ and real illumination values. The main objective of the optical characterization have known the concentration of solar power on the surface absorber tube, and the evolution of the maximum value of thermal flow depending on the incidence angle of solar radiation.

Figures $6 \mathrm{a}$ and $6 \mathrm{~b}$ illustrate the average heat flow distributions. We observe a good distribution of heat flux 
at the surface level of the absorber. We can say that our concentrator has a good overall optical behavior. Thus, we can conclude that the average distributions of heat flux provided the software ray tracing issues representative of real flux distributions by the parabolic trough concentrator.

\section{a) $\mathrm{DNI}=1000\left[\mathrm{~W} / \mathrm{m}^{2}\right]$}

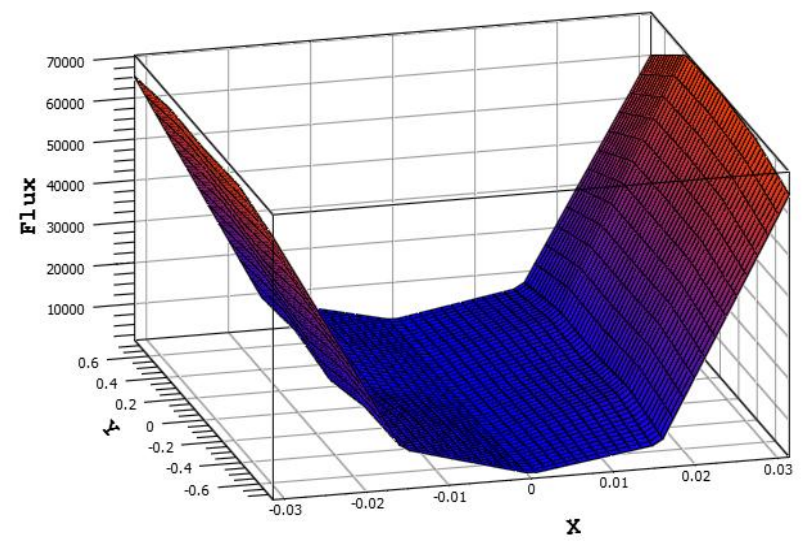

b) $\mathrm{DNI}=500\left[\mathrm{~W} / \mathrm{m}^{2}\right]$

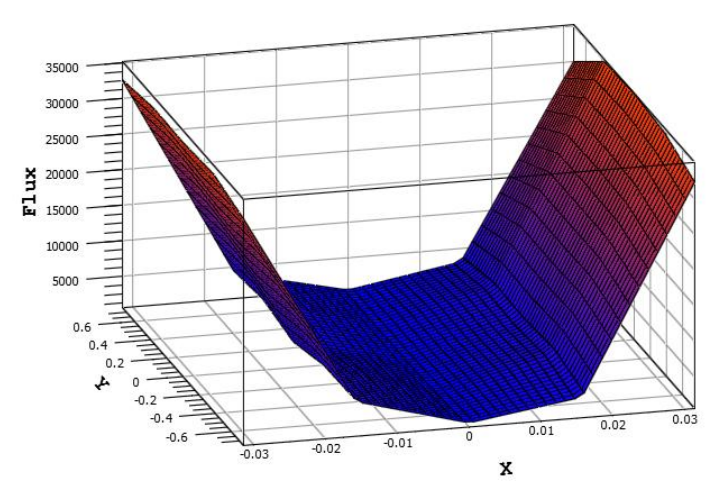

Figure 6. Flux intensity distribution at the absorber tube $\left[\mathrm{W} / \mathrm{m}^{2}\right]$.

Now we turn to the thermal analysis, the finite difference method was chosen to solve the non-linear equations of thermal balance. A calculation program using Matlab was developed after the discretization of the linear equations, which allowed us to obtain a set of numerical results, thus we will be able to know the performance of the concentrator. Figure 7 shows the evolution of optical performance versus time during the day of the study, while Figure 8 shows the evolution of thermal performance versus time for the same day.

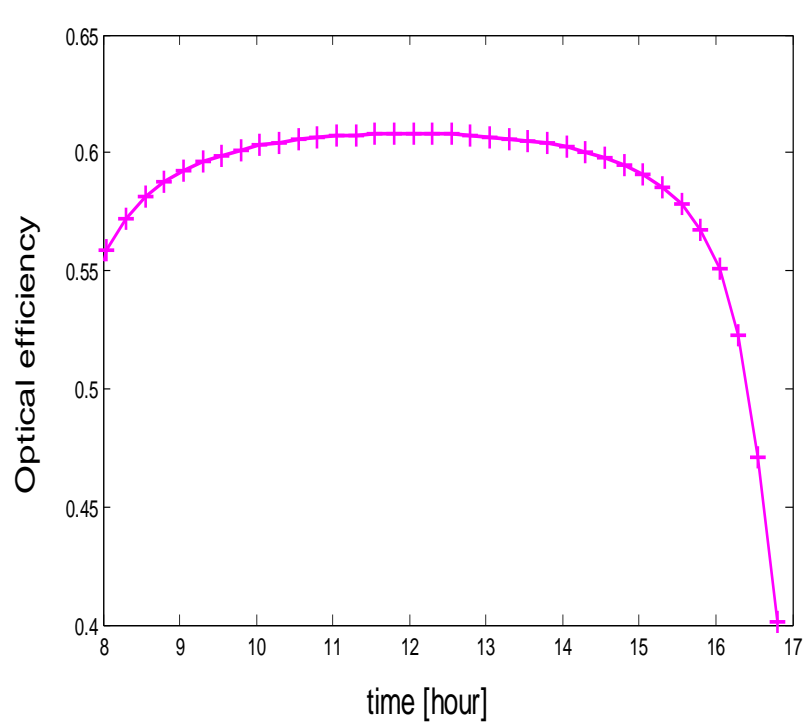

Figure 7. Evolution of optical efficiency.

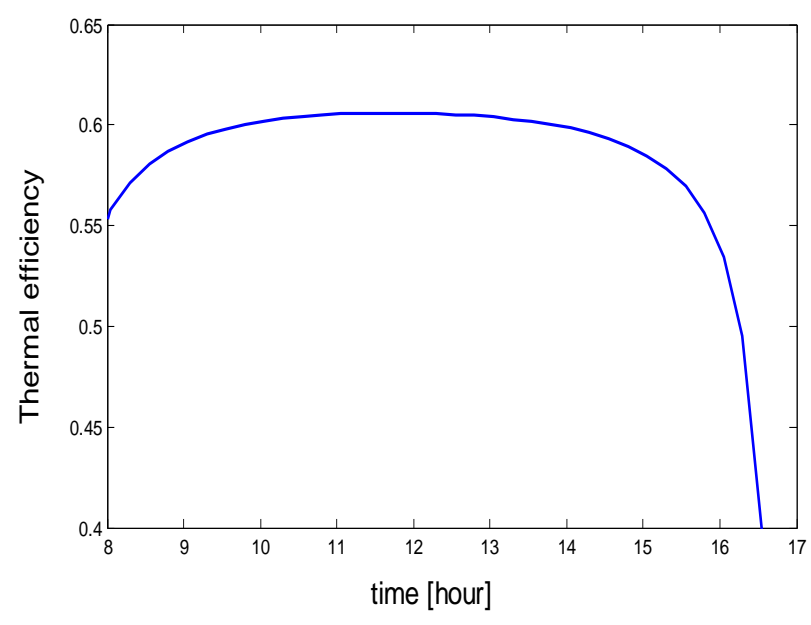

Figure 8. Thermal efficiency evolution versus the time.

It is noted that the thermal performance was equal to $60.61 \%$ at $12: 00$, after this time, the thermal efficiency decreases with the decreasing of solar radiation resources.

The receiver must absorb as much concentrated solar flux as possible, and convert it into thermal energy; this heat is transferred to water. The difference in temperature between the two faces (internal and external) of the absorber tube generates the creation of a heat flow. Figure 9 represents the variations of the absorber tube temperature, the fluid temperature and the glass temperature, where the wind speed $\left(\mathrm{W}_{\mathrm{w}}\right)$ during the day was equal to $4.5[\mathrm{~m} / \mathrm{s}]$ and the water temperature inside the absorbent tube was equal to $9^{\circ} \mathrm{C}$.

At the beginning of the day (at 08:00am), the temperature of the absorber tube was equal to the ambient temperature $(\mathrm{TA}=\mathrm{Tamb}=292 \mathrm{~K})$, after one hour of heating this temperature increases according to the direct solar radiation concentrated to the absorber, it reaches $302 \mathrm{k}$. It continues to increase where its value becomes stationary. In this case, the absorber is in a state 
of equilibrium, that is to say that all the surfaces of the absorber are at the same temperature, this state of equilibrium was very difficult to establish because of the influence of the wind. The maximum of the ambient temperature was reached between 12:00 and 14:00 hours, when the illumination is important.

The absorber tube is heated by concentrated direct solar radiation; this radiant energy absorbed by the absorber was converted into heat energy, which is transferred by convection to the water inside the receiver, which increases its temperature.

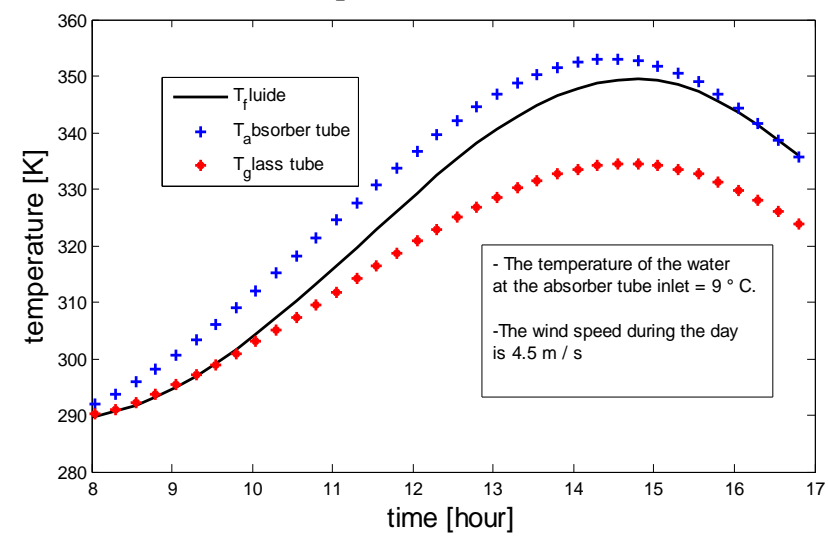

Figure 9. Evolution of the temperatures $\left(T_{A}, T_{F}\right.$ and $\left.T_{V}\right)$.

The heat transfer between the absorber tube and the water comes from the macroscopic movement of the water. According to figure 9, it is certain that the absorber tube temperature $\left(\mathrm{T}_{\mathrm{A}}\right)$, the water temperature $\left(\mathrm{T}_{\mathrm{F}}\right)$ and the glass temperature $\left(\mathrm{T}_{\mathrm{V}}\right)$ were directly related to the experimental conditions of weather conditions.

The results in figure 9 show the rapid heating of water by solar irradiation during the day. It is noted that the temperature of the absorber $\left(\mathrm{T}_{\mathrm{A}}\right)$ is close to $\left(\mathrm{T}_{\mathrm{F}}\right)$ which it has the maximum value at 14:55, we recorded an absorber temperature equal to $353(\mathrm{~K})$, and this is a sign of a good thermal insulation and low heat loss between the absorber tube and the surrounding air. The selective surfaces are taking advantage of different wavelengths of incident solar radiation, so the selectivity of the surface will result in a maximum absorption in the solar and infrared spectrum minimum. Therefore, the absorber tube has a high absorptivity for visible solar radiation and low emissivity for the long's wavelength infrared radiation due to the selective coating of the absorber. This coating can retain the greater part of the incident solar energy on the surface of the absorber and lose very little amount of heat radiation in the wavelength when the absorbent surface becomes hot.

The decrease of the absorber tube surface results in an increase in the concentration, therefore the performances are higher. For a test day with a constant volumetric flow, the temperature depends mainly on the $\mathrm{q}_{\text {absorbed }}(\mathrm{t})$, which is based on optical parameters, geometric of the concentrator and direct radiation received by the collector.

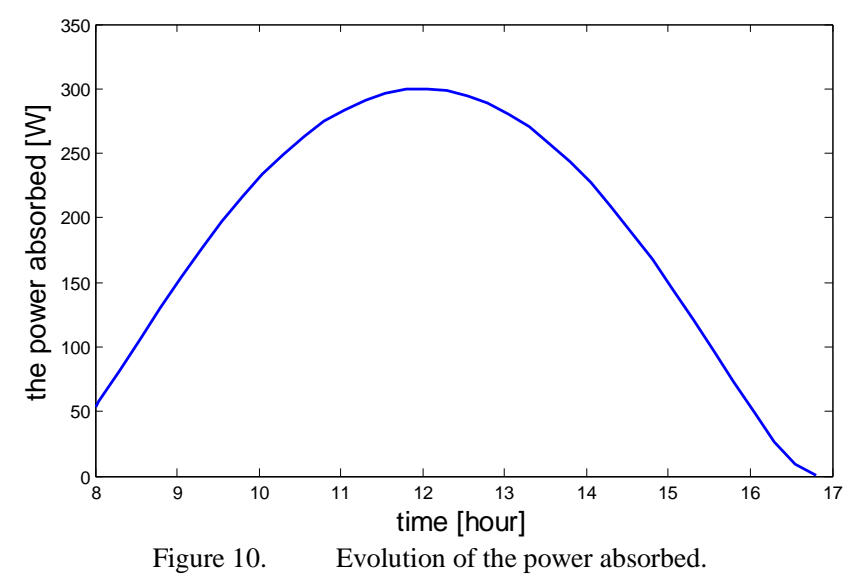

The inside of the absorber absorbs infrared radiation, which undergoes a temperature increase $\left(\mathrm{T}_{\mathrm{A}}\right)$ (greenhouse effect). Therefore, the temperature of the outer side is lower and close to the ambient medium subjected mainly to the wind speed, which creates convection to the outer side of the absorber, that is why the information about the meteorological data, including wind speed and ambient temperature are important parameters. The useful power absorbed by the receiver is used to heat the water inside the receiver and increases its temperature to a temperature of $353 \mathrm{k}$ at 14:55.

In nature, there are three modes of heat transfer, thermal transfer by conduction, by convection (natural and / or forced) and by radiation. From these three modes of transfer results three types of thermal losses: thermal losses by conduction, by convection and finally by radiation. For the PTC solar concentrator, the heat losses are important because the temperature of the absorber tube is high. Moreover, these concentrators require regular maintenance to maintain the optical quality of the mirrors subjected to dust and corrosion of the environment. Figure 11 shows the variation in the coefficient of thermal losses as a function of the difference in temperature between the absorber tube and the ambient temperature $\left(\mathrm{T}_{\mathrm{A}}-\mathrm{T}_{\mathrm{amb}}\right)$. In general, the heat loss coefficients depend on the insulation quality of PTC collector.

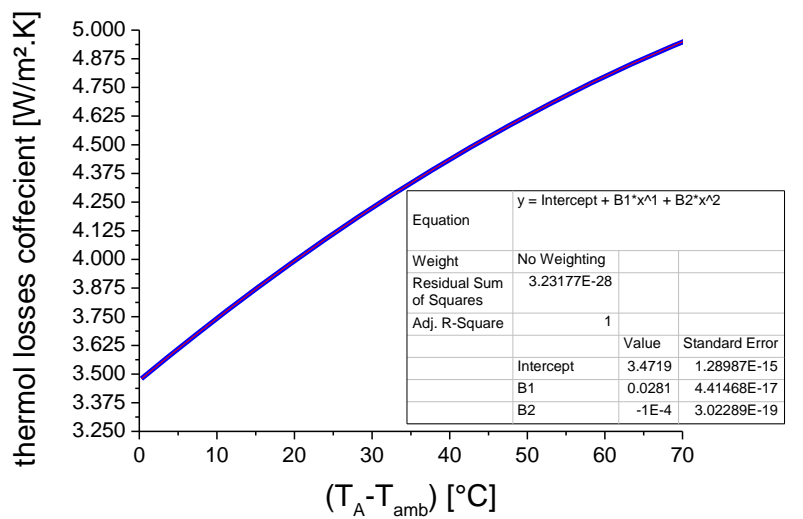

Figure 11. Evaluation of thermal losses coefficient. 
It can be seen from figure 11 that the coefficients of global heat losses $\left(\mathrm{U}_{\mathrm{L}}\right)$ increase slightly with increasing temperature. Thus, the coefficient of overall losses varies proportionally with the difference in temperature between the receiver tube and the ambient temperature $\left(\mathrm{T}_{\mathrm{A}}-\mathrm{T}_{\mathrm{amb}}\right)$, and this is due to the amount of heat absorbed by the absorber. UL increases with the increase of $\left(\mathrm{T}_{\mathrm{A}^{-}}\right.$ $\left.\mathrm{T}_{\mathrm{amb}}\right)$, it varies from 3.4 to $5 \mathrm{~W} / \mathrm{m}^{2} . \mathrm{K}$ where $0^{\circ} \mathrm{C}<\left(\mathrm{T}_{\mathrm{A}^{-}}\right.$ $\left.\mathrm{T}_{\mathrm{amb}}\right)<70^{\circ} \mathrm{C}$. Therefore, we see that the coefficient of losses varies in a slightly slow way; this is due to the range of operating temperature that is not high, and also to the good thermal insulation of the receiver.

Generally, the climatic conditions vary from season to another (intensity of solar radiation and the ambient temperature) affect the productivity of hot water. Through our study on linear concentrator [3-6, 10, 11], we can conclude that the results are very encouraging to exploit and build fields of linear concentrators in all regions of the country (north, south, east and west).

\section{Conclusion}

This work is a numerical study of a parabolic trough concentrator (PTC) in a volatile day in the winter (Low air temperature with some wind). Tap water was used as heat transfer fluid. The study was based on the numerical analysis of the energy balance equations of the absorbent tube, the water and the glass envelope surrounding the absorbent tube. According to this numerical solution, we can control the absorber temperature, the fluid outlet temperature and the glass temperature. The thermal efficiency of device exceeds $61 \%$, where the fluid temperature at outlet of the absorber tube is equal to 344 $[\mathrm{K}]$. The results are very encouraging for the development of this type of solar concentrator in the country.

\section{References}

[1] P. Bessemoulin and J. Oliviéri, "Le rayonnement solaire et sa composante ultraviolette," La Météorologie, vol. 8, no. 31, 2000, pp. 42-59.

[2] M. Ghodbane, B. Boumeddane, and N. Said, "Design and experimental study of a solar system for heating water utilizing a linear Fresnel reflector," Journal of Fundamental and Applied Sciences, vol. 8, no. 3, pp. 804-825. http://dx.doi.org/10.4314/jfas.v8i3.8, 01/09/2016 2016.

[3] M. Ghodbane, B. Boumeddane, and N. Said, "A linear Fresnel reflector as a solar system for heating water: theoretical and experimental study," Case Studies in Thermal Engineering, vol. 8, no. C, pp. 176-186.

http://dx.doi.org/10.1016/j.csite.2016.06.006, 2016.
[4] M. GHodbane, B. Boumeddane, and S. Largot, "Simulation numérique d'un concentrateur cylindro-parabolique en El Oued, Algérie," International Journal of Scientific Research \& Engineering Technology (IJSET), vol. 3, no. 2, 2015, pp. 68-74.

[5] M. Ghodbane, B. Boumeddane, and S. Largot, "Etude optique et thermique d'un concentrateur cylindro-parabolique en site d'Alger, Algérie," in IXth International Congress on Renewable Energy and the Environment, Djerba, Tunisie, 18-20 March 2015.

[6] M. Ghodbane, B. Boumeddane, S. Largot, and H. Berkane, "Modélisation d'un cycle de réfrigération solaire à éjecteur couplée à un concentrateur cylindro-parabolique," in International Conférence en Clean Cooling Technologies in the ME NA Regions (ICT3_MENA'2015) Bou Smail, W. Tipaza, 5-6 October 2015.

[7] M. Ghodbane and B. Boumeddane, "Optical modeling and thermal behavior of a parabolic through solar collector in the Algerian Sahara " AMSE JOURNALS-AMSE IIETA publication2017-Series: Modelling B, vol. 86, no. 2, 2017, pp. 406-426.

[8] M. Ghodbane and B. Boumeddane, "Estimating solar radiation according to semi empirical approach of PERRIN DE BRICHAMBAUT: application on several areas with different climate in Algeria," International Journal of Energetica, vol. 1, no. 1,2016 , pp. 20-29.

[9] M. Ghodbane and B. Boumeddane, "Numerical simulation of a solar-driven ejector refrigeration cycle coupled to a parabolic trough concentrator," International Journal of Chemical and Petroleum Sciences, vol. 5, no. 1, 2016, pp. 1-12.

[10] M. Ghodbane and B. Boumeddane, "A numerical analysis of the energy behavior of a parabolic trough concentrator," Journal of Fundamental and Applied Sciences, vol. 8, no. 3, 2016, pp. 671-691.

[11] M. Ghodbane and B. Boumeddane, "Numerical modeling of a parabolic trough solar collector at Bouzaréah, Algeria," international Journal of Chemical and Petroleum Sciences, vol. 4, no. 2, 2015, pp. 11-25.

[12] Z. Sen, "Flat plate collectors," in Solar Energy Fundamentals and Modeling Techniques: Atmosphere, Environment, Climate Change and Renewable Energy: Springer, 2008, pp. 246-249.

[13] A. Rabl, Active solar collectors and their applications. New York Oxford, Oxford University Press, 1985.

[14] S. A. Kalogirou, Solar Energy Engineering: Processes and Systems, 1st ed. Academic Press, 2009.

[15] D. Y. Goswami, F. Kreith, and J. F. Kreider, "OffNormal Incidence Effects," in Principles of solar engineering2nd ed.: Taylor \& Francis, 1999, p. 139. 
[16] D. Y. Goswami and F. Kreith, "Solar energy resources," in Energy conversion, T. F. group, Ed.: CRC Press, 2007, Chapter 5, pp. 1-9.

[17] M. Ghodbane, N. Moummi, B. Boumeddane, S. Largot, and H. Berkane, "Study and numerical simulation of solar system for air heating," Journal of Fundamental and Applied Sciences, vol. 8, no. 1, pp. 41-60. http://dx.doi.org/10.4314/jfas.v8i1.3, 2016.

[18] J. R. Vaillant, Utilisation et promesse de l'énergie solaire. 1978.

[19] J. Kramer. (2015). Kramer junction (californie) : la plus grande centrale solaire thermique du monde. Available: http://www.eco-conscient.com/art-53centrale-solaire-thermique-de-kramer-junctioncalifornie.html

[20] T. Wendelin, A. Dobos, and A. Lewandowski, "SolTrace: A Ray-Tracing Code for Complex Solar Optical Systems," Technical Report October 2013, Available: http://www.osti.gov/bridge.

[21] H. Chabahi, B. Boumeddane, and N. Said, "Dimensionnement et expérimentation d'un concentrateur linéaire a miroirs de fresnel," thesis of a state engineer in mechanical engineering, Mechanical Departement, Saad Dahlab University, Blida 1, Algeria, 2011.

[22] S. Bonnet, M. Alphilippe, and P. Stouffs, "Conversion thermodynamique de l'énergie solaire dans des installations de faible ou de moyenne puissance: Réflexion sur choix du meilleur degré de concentration," in Revue d'énergie renouvelable: $11^{\text {ème }}$ journée internationales de thermique, 2003, pp. $73-80$.

[23] J. A. Duffie and W. A. Beckman, Solar Engineering of Thermal Processes, 4th ed. Wiley, 2013.

\section{Nomenclatures}

Volume flow rate $\left(\mathrm{m}^{3} / \mathrm{s}\right)$

$\gamma \quad$ Intercept factor

$\mathrm{A}_{\mathrm{A}} \quad$ Absorber area $\left(\mathrm{m}^{2}\right)$

Ac Collector aperture area $\left(\mathrm{m}^{2}\right)$.

$\mathrm{C}_{\mathrm{A}} \quad$ Specific heat of the absorber $(\mathrm{J} / \mathrm{kg} \mathrm{k})$.

$\mathrm{C}_{\mathrm{F}} \quad$ Specific heat of the fluid $(\mathrm{J} / \mathrm{kg} \mathrm{k})$.

$\mathrm{Cp}$ Thermal capacity $(\mathrm{J} / \mathrm{kg} \mathrm{k})$.

$\mathrm{D}_{\mathrm{A}, \mathrm{ext}} \quad$ External diameter of the absorber (m).

$\mathrm{D}_{\mathrm{A}, \mathrm{int}} \quad$ Internal diameter of the absorber $(\mathrm{m})$.

$\mathrm{D}_{\mathrm{V} \text {,ext }} \quad$ External diameter of the glass tube $(\mathrm{m})$.

$\mathrm{D}_{\mathrm{V} \text {,int }}$ Internal diameter of the glass (the transparent envelope) (m).

$h_{v} \quad$ Coefficient of transfer by convection of the wind $\left(\mathrm{W} / \mathrm{m}^{2} . \mathrm{K}\right)$.

$\mathrm{K}_{\mathrm{cam}} \quad$ Angle of incidence correction factor modified

$\mathrm{q}_{\text {absorbed }}$ Heat absorbed in the absorber tube $\left(\mathrm{W} / \mathrm{m}^{2}\right)$.

Heat quantity lost to the outside

$\mathrm{q}_{\text {exte }} \quad$ (convection + conduction) between the glass and ambient $\left(\mathrm{W} / \mathrm{m}^{2}\right)$.

$\mathrm{q}_{\text {int }} \quad$ Internal heat (convection + conduction) between the glass and ambient $\left(\mathrm{W} / \mathrm{m}^{2}\right)$.

Heat exchanged by convection between the absorber and the fluid $\left(\mathrm{W} / \mathrm{m}^{2}\right)$.

$\mathrm{S}_{\mathrm{e}} \quad$ The effective area of a sensor reflector $\left(\mathrm{m}^{2}\right)$.

$\mathrm{W}_{\mathrm{w}} \quad$ Wind velocity $(\mathrm{m} / \mathrm{s})$.

$\mathrm{T}_{\mathrm{A}} \quad$ Temperature of the absorber $(\mathrm{K})$.

$\mathrm{T}_{\mathrm{amb}} \quad$ Ambient temperature $(\mathrm{K})$.

$\mathrm{T}_{\mathrm{F}} \quad$ Fluid temperature (K).

$\mathrm{T}_{\mathrm{V}} \quad$ Temperature of the glass $(\mathrm{K})$.

$\mathrm{U}_{\mathrm{L}}$ Overall coefficient of heat loss (W/m².K).

$\varepsilon_{\mathrm{A}} \quad$ Emissivity of the absorber tube

Emissivity of the casing transparent glass

$\rho_{\mathrm{A}} \quad$ Density of the absorber $\left(\mathrm{kg} / \mathrm{m}^{3}\right)$.

$\rho_{\mathrm{F}} \quad$ Fluid density $\left(\mathrm{kg} / \mathrm{m}^{3}\right)$.

$\sigma \quad$ Stefan-Boltzmann constant $\left(\mathrm{W} / \mathrm{m}^{2} \cdot \mathrm{K}^{4}\right)$. 